\title{
Transport delay assessment at signalized intersections feeding focal points
}

\author{
Anton Zedgenizov ${ }^{1 *}$, Aleksandr Solodkiy ${ }^{2}$, and Ivan Silinsky ${ }^{1}$ \\ ${ }^{1}$ Department of Oil and Gas Engineering, Irkutsk National Research Technical University, 83, \\ Lermontov str., Irkutsk, 664074, Russia. \\ ${ }^{2}$ Department of Transport Systems, Saint Petersburg State University of Architecture and Civil \\ Engineering, 4, Vtoraya Krasnoarmeiskaya str., Saint Petersburg, 190005, Russia.
}

\begin{abstract}
The article focuses on the issues of organizing transport services for visitors of the focal points (FP) using individual transport (IT). The main factors influencing the generation of transport demand arising from the focal points functioning are considered. The authors present the mathematical models that allow assessing the following variables: the traffic flow intensity arising during the transport service of individual transport users both at the entrance to the focal point territory and at the exit from it; the value of the load factor of the given group of lanes at the signalized intersection; the value of delay that occurs when visiting focal units using individual transport. The authors elaborate recommendations for the practical application of the considered mathematical models while organizing transport services for focal points visitors using individual transport.
\end{abstract}

\section{Introduction}

The current trends of urbanization, enlargement of cities and their influence zones make specialists from various industries create a single harmonious environment that allows people to move for labor, cultural, household, and other purposes with minimal time losses (time losses for the labor movements are regulated in professional literature [1,9]). To be precise, it should be noted that the key role in creating such an environment is played by urban planning decisions made at various stages of urban and transport planning; they refer to both lay-outs of agglomerations and integrated schemes of traffic management. In addition, the most important factors influencing the development of urbanized territories are environmental restrictions limiting the possibility of locating production sites and special-purpose facilities. On the other hand, transport communications act as a limitation of the speed of passengers' movements in urbanized areas; they include not only transportation systems, but also the entire accompanying infrastructure. First of all, the transport infrastructure consists of a street and road network having various categories, technical means of traffic management and places for temporary storage of individual vehicles (parking lots). The travel time to the destination is estimated by the average speed

\footnotetext{
*Corresponding author: azedgen@gmail.com
} 
of the movement on the selected route, whereas the time required to place the car in the parking lot and the subsequent delays associated with leaving it depends on the characteristics of the focal points near which the parking lot is located. Therefore, the development and research of tools that allow assessing the value of the delay when visiting focal points seem to be an important scientific and real-life task.

\section{Materials and methods}

It is obvious that the characteristics of FPs functioning can significantly affect the delays resulting from visiting them. Several factors can influence these delays: first of all, the generating capacity of a FP; its type (according to the type of activity); the duration of parking which will be partially influenced by the speed of servicing the visitors; the number and location of feeding intersections; the traffic management at these intersections; the intensity of the transit flow of vehicles that have the priority over the vehicles entering or exiting the FP territory; traffic and navigation management in the FP territory. The above list of factors makes it obvious that they need to be structured and classified. The first class should include the factors associated with the FP functioning, that is, the factors influencing the development of the traffic flows entering/exiting the FP; in the context of this article these flows can be called the intensity of entry and exit. The second class of factors is associated with the elements of the street and road network (intersections) and traffic management system maintained by technical means applied in international practice, including the use of smart transport systems.

The assessment of the intensity of traffic flows running to/from the FP with reference to the entire list of the above factors is possible on the basis of the model [2]:

$$
N_{T I}=E_{F P} \cdot \frac{d_{I T}}{P_{I T}} \cdot k_{d i}
$$

where $E_{F P}$ stands for the transport demand, persons per hour; $d_{I T}$ means the ratio of people using individual transport during the definite hour; $P_{I T}$ - the average number of people in a vehicle (IT), persons; $k_{d i}$ - coefficient of daily irregularity for the definite hour.

Transport demand is usually assessed on the basis of its generating capacity and depends on the type of a FP, its location under the city plan, as well as its area. As a rule, transport demand is determined experimentally and described by empirical dependencies [5]. The proportion of visitors using IT depends on the type of a FP, on the level of automobilization in the city (region), etc. Generally, the intensity of entry differs from the intensity of exit due to different stay time in the territory of a FP and is determined by the coefficient of daily irregularity.

Actually, the factors of the second class implies that it is necessary to assess the throughput capacity of the intersection feeding the FP, which depends on the duration of the permissive signal, and on the individual characteristics of the group of lanes evaluated through the flow intensity.

$$
x=\frac{(1.5 L+5) \cdot\left(\sum_{i=1}^{n} \frac{N_{i}}{S_{i}}\right)}{\left(\frac{1.5 L+5}{1-\sum_{i=1}^{n} \operatorname{Max} \frac{N_{i}}{S_{i}}}-L\right) \cdot\left(1-\sum_{i=1}^{n} \operatorname{Max} \frac{N_{i}}{S_{i}}\right)},
$$

where, $L$ - time lost during the cycle, $N_{i}$ - traffic intensity in the definite group of lanes, units per hour; $S_{i}$ - saturation flow in the definite group of lanes, units per hour.

It should be noted that the intensity of the traffic flow at the entrance or exit of the FP is calculated by expression (1), it is this parameter that is the most difficult to assess; the 
throughput capacity is determined by the saturation flow with reference to geometrical characteristics and other features of the intersection.

The classical mathematical model of delay [17] - Webster's formula:

$$
d=0.9\left[\frac{\mathrm{C}(1-g / C)}{2(1-g / C) x}+\frac{x^{2}}{2 N(1-x)}\right]
$$

where $d$ - average delay during the cycle, $\mathrm{s} ; C$ - length of the regulation cycle, $\mathrm{s} ; g-$ effective green signal duration, $\mathrm{s} ; x$ - coefficient of the loading (ratio of intensity to throughput capacity); $N$ - intensity of the traffic flow, units per hour.

This is the formula that assumes the necessity of introducing of a loading coefficient $\mathrm{x}$ along with the traffic light signaling mode. Besides, in the specialized literature of the "western" world, you can find a dozen other models for assessing the delay and its derivative - the queue length $[10,11,12,13,14,15,16,6,7,8]$. The main emphasis of these formulae is placed on taking into account both the randomness of the vehicles arrival and the delay resulting from the queue of vehicles at the start of the permissive signal for the definite group of lanes.

\section{Results}

Thus, having such instruments as (1-3), as well as the world scientific experience aimed at assessing delays at signalized intersections, it is possible to derive an integrated model for assessing the delay during the transport service of focal points. The awkwardness of the integrated formula causes the necessity of carrying out the calculations by stages. At the first stage the intensity of traffic flows (1) running to/from the considered focal points is determined on the basis of transport demand and a number of other parameters the values of which can be found in the appendix of the monograph $[3,4]$. At the second stage, the load factor (2) is determined with reference to the current operating mode of the traffic lights and the intersection parameters. And finally, at the third stage, the value of delay is determined which allows, in particular, assessing the length of the vehicles queue.

\section{References}

1. Trip Generation Handbook, 2nd Edition: An ITE Recommended Practice. Washington, DC: ITE (2004)

2. Burkov D.G., Zedgenizov A.V. Improvement of the mathematical model for calculating the intensity of vehicles to focal points in urbanized areas. Transport of Russia: problems and prospects - 2018: proceedings of the International scientific and practical conference, November 13-14, 2018, St. Petersburg: ITP RAS. - St. Petersburg. Vol. 1. P. 317-321 (2018)

3. Zedgenizov A.V. Methods of traffic management based on the assessment of transport demand for the focal points according to their location in urbanized areas. Information technologies and innovations in transport / proceedings of the 5th International scientific and practical conference (May 22-23, 2019, Oryol) // ed. by Doctor of Technical Sciences, Professor A.N. Novikov. Oryol: OSU named after I.S. Turgenev, 47-52 p. (2020)

4. Zedgenizov A.V. Assessment of the quality of traffic management on the basis of transport demand: monograph. - Irkutsk: Publishing house of INRTU, - 196 p. (2019)

5. Zedgenizov A.V. Assessment of transport demand based on the parameters of focal points functioning in urbanized areas. The world of transport and technological 
machines, № 3 (66), 2019 July-September. - Oryol: Publishing house of OSU named after I.S. Turgenev, - 91-97 p. (2019)

6. Zyryanov V.V. Criteria for evaluating traffic conditions and traffic flow models. Kemerovo: Kuzbass Polytechnic Institute, - 164 p. (1993)

7. Kapitanov V.T., Shauro S.V. On the issue of transport delays at the isolated intersection. - Proceedings / VNII BD Ministry of Internal Affairs of the USSR, issue 3, P. 65-74. (1978)

8. Levashev A.G., Mikhailov A.Yu., Golovnykh I.M. Design of signalized intersections: study guide. - Irkutsk: Publishing house of ISTU, - 208 p. (2007)

9. Code SP 42.13330.2016. Urban planning. Planning and Development of Urban and Rural Settlements, revised edition of SHiP 2.07.01-89. - Moscow, Ministry of Construcion of RF, - 94 p. (2016)

10. Highway Capacity Manual 2000. - Transportation Research Board, National Research Council. - Washington, D.C., USA, - 1134 p. (2000)

11. Highway Capacity Manual 2010. - Transportation Research Board, National Research Council. - Washington, D.C., USA, - 1134 p. (2010)

12. May Adolf D. Traffic flow fundamentals // Prentice Hall, Englewood Cliffs, New Jersey, 464 p. (1990)

13. Newell G. F. Theory of Highway Traffic Signals. // UCB-ITS-CN-89-1, Institute of Transportation Studies, University of California. (1989)

14. Olszewski P. Traffic Signal Delay Model for Non-Uniform Arrivals. // Transportation Research Record, 1287, pp. 42-53. (1990)

15. Shnabel W. Strassen-Verkehrstechnik. // Verlag fuer Bauwesen GmbHBerlin, 608 p. (1997)

16. Shnabel W. Verkehrsplanung. // Verlag fuer Bauwesen GmbH-Berlin, 432 p. (1997)

17. Tarko A. Traffic Flow at Signalized Intersections // Traffic flow theory, Chapter 9, 32 p. www.tfhrc.gov/its/tft/chap9.pdf 